\title{
Carta de Edmund Husserl a von Hofmannsthal, 12.01.1907
}

Muy apreciado señor von Hoffmannsthal,

Me ha comentado ${ }^{1}$ usted cuán dificil se le ha vuelto la vida debido a un constante aluvión de correspondencia. Pero ahora que me ha honrado usted con un exquisito obsequio ${ }^{2}$, no me queda más remedio que agradecerle. Ha de cargar, por tanto, con las consecuencias del malvado hecho y soportar también esta carta. Le pido profundamente disculpas, dicho sea de paso, por no haberle agradecido de inmediato. Sintesis de pensamiento largamente buscadas se me revelaron súbitamente, como caídas del cielo. Tuve que fijarlas deprisa. Sus "dramas breves", que tuve a mi lado todo el tiempo, me fueron un gran estímulo, a pesar de que solo pude leerlos de un modo discontinuo.

Los "estados internos" que su arte retrata como puramente estéticos, o no propiamente retrata, sino eleva a la esfera ideal de la belleza estética pura, tienen para mí, en esta objetivación estética, un interés muy especial. Esto es, no solo para el amante del arte que hay en mí, sino también para el filósofo y "fenomenólogo". Los muchos años de esfuerzo en torno al claro sentido de los problemas filosóficos fundamentales y, luego, acerca del método para su resolución, me trajeron como logro permanente el método "fenomenológico". Este método exige, con respecto a toda objetividad, una toma de posición [Stellungnahme] que diverge de manera esencial de la toma de posición "natural» y está estrechamente relacionado con aquella posición y actitud a la que nos traslada su arte, como puramente estética, con respecto al objeto representado

\footnotetext{
* En: Husserl, E., Briefwechsel. Bd. VII. Wissenschaftlicherkorrespondenz. Husserliana Dokumente III, Dordrecht: Kluwer, 1994, pp. 133-136.

1 Hugo von Hofmannsthal había visitado a Husserl el 6 de diciembre 1906, con ocasión de una conferencia impartida en Gotinga por invitación de Theodor Lessing [N.d.E.].

2 Probablemente: H. von Hofmannsthal, H., Kleine Dramen, Leipzig 1906 (no encontrado en la biblioteca de Husserl) [N.d.E.].
} 
y al mundo entero circundante. La intuición de una obra de arte puramente estética se lleva a cabo en estricta desconexión [strenge Ausschaltung] de cualquier toma de posición existencial del intelecto y de cualquier toma de posición del sentimiento y de la voluntad que presuponga una toma de posición existencial. O mejor: la obra de arte nos traslada (nos fuerza casi) al estado de la intuición puramente estética, que excluye aquellas tomas de posición. Cuanto más resuena o es vivamente invocado el mundo existencial, [134] cuanto más requiera de él la obra de arte en la toma de posición acerca de la existencia (por ejemplo, como naturalista ilusión de los sentidos: la verdad natural de la fotografia), menos puramente estética es la obra. (También a esto pertenece toda clase de "tendencia".) La actitud espiritual [Geisteshaltung] natural, la de la vida actual, es absolutamente "existencial". Las cosas que están ahí ante nosotros de modo sensible, las cosas acerca de las cuales habla el discurso científico actual, las ponemos como realidades efectivas [Wirklichkeiten] y sobre estas posiciones de existencia se fundan actos emotivos y volitivos: alegría de que esto es; tristeza de que es o no es; deseo de que aquello pueda ser, etc. (= tomas de posición existenciales de la emoción [Gemüt]): el polo opuesto a la actitud espiritual de la intuición puramente estética y del estado afectivo [Gefühlslage] que le corresponde . Pero no menos también el polo opuesto a la actitud espiritual puramente fenomenológica, la única en la que los problemas filosóficos pueden ser resueltos. Porque también el método fenomenológico exige la estricta desconexión de todas las tomas de posición existenciales. Ante todo en la crítica del conocimiento ${ }^{3}$.

Tan pronto como la esfinge del conocimiento ha formulado su pregunta, tan pronto como hemos mirado en el abismal problema de la posibilidad de un conocimiento que solo se efectúa en las vivencias subjetivas y que, no obstante, capta una objetividad existente en sí, nuestra posición hacia todo conocimiento predado y hacia todo ser predado - hacia toda ciencia y toda pretendida realidad-se transforma radicalmente. Todo [se vuelve] cuestionable, todo [se vuelve] incomprensible, enigmático. El enigma solo es resoluble si nos ponemos sobre su suelo, si tratamos todo conocimiento precisamente como cuestionable y, por lo tanto, no aceptamos ninguna existencia como predada. Con ello, toda ciencia y toda realidad (también la del propio yo) se tornan meros "fenómenos". Ahora solamente queda una cosa: clarificar, en el ver [Schauen] puro (en el puro análisis y la abstracción visivos [schauende]), el sentido inmanente a los

3 Dejo de lado los dominios paralelos de la crítica filosófica de la "razón" "práctica" y de la "estética", en general, de la razón "valorativa" [Nota de Husserl]. 
meros fenómenos sin jamás excederlos, esto es, sin presuponer ni utilizar como dadas ninguna de las existencias trascendentes en ellos mentadas. Por tanto, clarificar lo que el conocimiento como tal y la conocida objetualidad como tal mienta, y lo que mienta según su esencia inmanente. Esto, para todos los tipos y formas de "conocimiento". Si todo conocimiento es cuestionable, entonces el fenómeno "conocimiento" es precisamente la única dación [Gegebenheit], y antes de admitir cualquier conocimiento como válido debo mirar e investigar de modo puramente visivo (puramente estético, por así decirlo): [135] lo que la validez en general mienta, esto es, lo que el conocimiento como tal mienta, con y en su "objetualidad conocida" [erkannte Gegenständlichkeit]. Desde luego, para investigar de modo "visivo" el conocimiento, no debo ceñirme, sin embargo, al cuasi-conocer meramente verbal (pensamiento simbólico), sino al conocer propiamente "evidente" e "intelectivo" [einsehende], a pesar de que aquel conocer simbólico, en su relación con el evidente, también requiere de un análisis fenomenológico de esencias.

El ver fenomenológico está por tanto estrechamente relacionado con el ver estético en el arte "puro"; no es obviamente un ver para disfrutar estéticamente, sino más bien para, desde él, volver a investigar, conocer y constituir constataciones cientificas de una nueva esfera (la esfera filosófica).

Una cosa más. El artista que "observa” el mundo para obtener de él "conocimiento" del ser humano y de la naturaleza para sus propios fines se comporta hacia él de modo semejante al fenomenólogo. Esto es: no como observador naturalista y psicólogo, no como observador práctico de lo humano, como si se dedicara a las ciencias naturales o humanas. En tanto lo contempla, el mundo se convierte para él en fenómeno; su existencia le es indiferente, tal como para el filósofo (en la crítica de la razón). Solo que el artista no aspira, a diferencia del filósofo, a indagar y asir en conceptos el "sentido" del fenómeno del mundo, sino a apropiárselo de manera intuitiva a fin de reunir, de la abundancia de formaciones [Gebilde], los materiales para las configuraciones estéticas creativas.

¡El auténtico e incorregible profesor! No puede abrir la boca sin acabar dando una clase. Pero, por suerte, a la "esencia" filosófica de una clase pertenece el no exigir una respuesta y lo mismo se aplica para la esencia de la "libertad académica", la que permite elegir a voluntad si echarse una siesta o saltarse la clase.

Le deseo, pues, estimado señor von Hofmmansthal, todo lo mejor para el nuevo año. Y lo que a usted deseo, se lo deseo también a todo el mundo 
que se interesa tanto por su desarrollo y crecimiento interiores con sus flores y sus frutos.

P.D. Me reservaré decir alguna cosa acerca de su obra. Pienso que el elogio, como las críticas y el discurso erudito de cualquier tipo, le son a usted bastante indiferentes. Y que las tres reglas de oro del artista (en el sentido más amplio), que son a la vez los secretos públicos de toda verdadera grandeza, le son sin duda evidentemente conocidos, [136] a saber: 1) El artista posee genio; lo ha de tener, si no, no es un artista. 2) Sigue pura y exclusivamente a su daimon, que lo impulsa desde el interior a actuar de un modo ciegamente intuitivo. 3) Todos los demás lo saben mejor de todos modos; así que el artista los contempla a todos ellos: de modo meramente estético o fenomenológico.

Con nuestros más sinceros y mejores saludos,

Muy atentamente

E. Husserl

Traducción de Ricardo Mendoza-Canales

Universidad Autónoma de Barcelona

Recibido: 26/01/2017

Aprobado: 26/07/2017 